\title{
Análise de Estabilidade em Interações de tipo Hospedeiro-Parasita: o caso generalizado
}

\author{
Mariana Uzeda-Cildoz* \\ Universidade Estadual do Oeste do Paraná - Centro de Ciências Exatas \\ 85851-000, Foz do Iguaçu, PR \\ E-mail: mariana.uzeda@gmail.com \\ Sonia Palomino \\ Universidade Federal de Santa Catarina - Departamento de Matemática \\ 88040-900, Campus Trindade, Florianópolis, SC \\ E-mail: sonia.palomino@ufsc.br
}

\begin{abstract}
RESUMO
Num habitat com $n \geq 2$ espécies podem se destacar interações de tipo harmônico e desarmônico. As interações harmônicas ou positivas são aquelas onde há vantagens para pelo menos uma das espécies sem prejuízo nenhum para todas as espécies participantes. Já as interações desarmônicas ou negativas são aquelas onde pelo menos uma das espécies participantes é prejudicada, podendo existir benefícios para uma delas. As principais interações do tipo desarmônico são a Competição e a Predação e a do tipo harmônico, o Mutualismo [3].

- No trabalho desenvolvido em [4] usamos alguns problemas práticos para apresentar alguns modelos bidimensionais de Predação, Competição e Mutualismo, focando especificamente naqueles de tipo mutualístico. As interações mutualísticas apresentadas foram de tipo simbiótico, não-simbiótico e endossimbiótico e mostramos também o estudo de estabilidade assim como os tipos de equilíbrio dessas interações.

Neste trabalho, estudaremos a estabilidade da interação generalizada de espécies nos casos de predação e competição. Existem muitas aplicações desses modelos, por exemplo, nos problemas com interações do tipo hospedeiro-parasita, no uso de herbicidas, na epidemiologia, no crescimento de tumores, entre outros.

Com o intuito de estudar a estabilidade de alguns modelos com interações de tipo hospedeiroparasita, num primeiro momento, usaremos os modelos de Lotka-Volterra com crescimento logístico inserindo a função switching como variante (Palomino et al [1, 2]). Também, levaremos em consideração a coexistência ou não coexistência das espécies assim como simulações da evolução das mesmas serão apresentadas.
\end{abstract}

Palavras-chave: Dinâmica de Populações, Hospedeiro-Parasita, Estabilidade.

\section{Referências}

[1] S. Palomino-Bean et al, Coexistência de espécies em sistemas Presa-Predador com Switching, Tendências em Matemática Aplicada e Computacional, Tendências em Matemática Aplicada e Computacional, TEMA, vol. 7 (2), pp. 317-326, 2006.

[2] K. Preedy et al, Disease induced dynamics in host-parasitoid systems: chaos and coexistence, J. R. Soc. Interface, vol. 4, pp. 463-471, 2007.

[3] J. Roughgardem, "Primer of Ecological Theory”, Prentice Hall, New Jersey, 1998.

[4] M. Uzeda-Cildoz, "Modelos Populacionais Unidimensionais e Bidimensionais aplicados à Aquicultura", Monografia de Especialização, Dpto. de Matemática, UFSC, 2011.

* Aluna do Programa de Pós-graduação Stricto Sensu em Engenharia de Sistemas Dinâmicos e Energéticos da Universidade Estadual do Oeste do Paraná. 